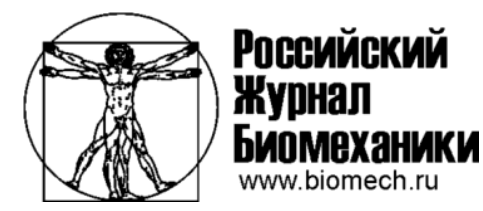

\title{
РОЛЬ ЛОКАЛЬНЫХ НАРУШЕНИЙ ГЕМОДИНАМИКИ ПРИ ПАТОЛОГИЧЕСКОЙ ИЗВИТОСТИ СОННЫХ АРТЕРИЙ В РАЗВИТИИ СОСУДИСТОЙ МОЗГОВОЙ НЕДОСТАТОЧНОСТИ
}

\author{
М.л. Каплан ${ }^{1}$, Д.Н. Бонцевич ${ }^{1}$, С.В. Шилько 2 \\ ${ }^{1}$ Кафедра хирургических болезней № 3 с курсом сердечно-сосудистой хирургии Гомельского \\ государственого медицинского университета, Республика Беларусь, 246000, Гомель, ул. Ланге, 5, e-mail: \\ kaplan_md@mail.ru \\ 2 Лаборатория механики композитов и биополимеров Института механики металлополимерных систем \\ им. В.А. Белого Национальной академии наук Беларуси, 246050, Республика Беларусь, Гомель, \\ ул. Кирова, 32a, e-mail: Shilko_mpri@mail.ru
}

\begin{abstract}
Аннотация. Турбулизация кровотока у пациентов с патологической извитостью внутренних сонных артерий при скорости свыше $1 \mathrm{~m} / \mathrm{c}(\operatorname{Re}>1140)$, возникновение пристеночных вихрей и увеличение скорости кровотока в результате уменьшения гидравлического диаметра сонных артерий приводят к увеличению гемодинамического сопротивления сосудистой сети и гипоперфузии головного мозга. Многообразие форм и сложность геометрической конфигурации артерий при их патологической извитости требуют индивидуального подхода при определении показаний к хирургическому лечению и выборе способа операции. В работе предложены объективные биомеханические критерии, основанные на инструментальных клинических исследованиях гемодинамических нарушений и определении градиента давления на участках изменения геометрии сосудов. Комплексное использование анатомических и гемодинамических параметров позволяет оценить градиент давления и энергетические потери при патологической извитости внутренних сонных артерий любой геометрической конфигурации. Установлено расширение проксимального участка артерии по отношению к патологическому изгибу, обусловленное тем, что диаметр устья внутренней сонной артерии при односторонней патологической извитости превышает диаметр устья на контралатеральной стороне. В артериях диаметром 4 мм появление пристеночных вихревых течений происходит при скорости 1,2 м/с, а полная турбулизация - при скорости 1,4 м/с. При увеличении диаметра сонных артерий до 6 мм скорость кровотока, при которой появляются пристеночные вихревые течения, составляет 0,8 м/с, а турбулизация кровотока регистрируется при скорости 1 м/с.
\end{abstract}

Ключевые слова: патологическая извитость сонных артерий, кинкинг, койлинг, локальные нарушения гемодинамики, градиент давления, энергетические потери.

\section{ВВЕДЕНИЕ}

Гемодинамические отклонения и сосудистые заболевания головного мозга представляют серьезную социально-экономическую проблему, являясь одной из главных причин инвалидизации и смертности среди пациентов молодого возраста [6], а также причиной травм и снижения результативности в видах спорта с высокой

(C) Каплан М.Л., Бонцевич Д.Н., Шилько С.В., 2015

Каплан Марк Львович, аспирант кафедры хирургических болезней № 3 с курсом сердечно-сосудистой хирургии, Гомель

Бонцевич Дмитрий Николаевич, к.м.н., доцент кафедры хирургических болезней № 3 с курсом сердечнососудистой хирургии, Гомель

Шилько Сергей Викторович, к.т.н., заведующий лабораторией, Гомель 
степенью координации движений. Патологическая извитость сонных артерий занимает значимое место в структуре заболеваний, вызывающих недостаточность мозгового кровообращения, уступая лишь атеросклеротическому поражению сосудов данной анатомической области [4]. Возможность эффективного хирургического лечения пациентов $\mathrm{c}$ измененной церебральной гемодинамикой позволяет проводить адекватную профилактику ишемического инфаркта головного мозга и предотвратить развитие инвалидизирующих и смертельно опасных осложнений [2].

Так, локальные изменения гемодинамики в бифуркациях сосудов и местах отхождения артериальных ветвей рассматривались в работе [11] с целью выявления факторов риска атеросклеротического поражения. Исследование гемодинамических нарушений при наличии патологической извитости артерий в $[10,13]$ показало возможность развития изучаемой патологии в результате действия повышенного артериального давления на стенки кровеносных сосудов. Для некоторых форм патологической извитости выполнено численное моделирование кровотока с использованием трехмерного нестационарного уравнения Навье - Стокса $[3,5]$, но отсутствие обобщенного биомеханического описания приводит к необходимости трудоемкого параметрического анализа гемодинамики в местах сложной геометрии сосуда для каждого пациента. Весьма актуальна разработка комплексного (аналитического и статистического) подхода [8], позволяющего выявлять закономерные локальные гемодинамические нарушения и оптимизировать хирургическое лечение при различных формах данной патологии.

\section{ЦЕЛЬ ИССЛЕДОВАНИЯ}

Целью настоящего исследования было изучение особенностей локальных нарушений гемодинамики при патологической извитости внутренних сонных артерий сложной геометрической конфигурации, позволяющих обосновать роль данной патологии в развитии сосудистой мозговой недостаточности.

\section{МАТЕРИАЛЫ И МЕТОДЫ}

Определение потери давления крови при прохождении по патологически извитому кровеносному сосуду выполнялось на участке внутренней сонной артерии от устья до входа в височную кость. Этот участок внутренней сонной артерии наиболее часто подвержен развитию конфигурационных аномалий и не имеет ветвей, что с позиций прикладной гидромеханики позволяет считать его «простым трубопроводом» [6] и использовать расчетные зависимости для местного гидравлического сопротивления (потери давления на участке изменения геометрии артерии) и потери давления на трение по длине артерии. Учитывая разнообразие геометрических форм измененного сосуда при патологической извитости, расчеты гемодинамических параметров выполнялись для каждого пациента исследованной группы. К этим параметрам относятся: число Рейнольдса для определения режима течения крови; местные потери давления по формуле Вейсбаха; потери давления на местное сопротивление; потери давления по длине измененной артерии, обусловленные трением о стенки сосуда и трением слоев (вихрей) крови между собой.

В расчетах использовались геометрические характеристики измененных внутренних сонных артерий (диаметр, длина, угол изгиба) на участке от устья до входа в череп, полученные по результатам спиральной компьютерной томографии с контрастированием либо магнитно-резонансной томографии с $3 D$-реконструкцией. Скоростные характеристики кровотока у каждого пациента определялись путем ультразвукового дуплексного сканирования сосудов шеи. 
При моделировании вводились следующие допущения:

1. стенки артерии считались недеформируемыми;

2. диаметр внутренней сонной артерии для каждого пациента принимался неизменным;

3. использовались скоростные характеристики и параметры геометрии сосудов при гемодинамически значимых формах патологической извитости внутренней сонной артерии у пациентов с клиническими проявлениями каротидной сосудистой мозговой недостаточности;

4. динамическая вязкость и плотность крови подразумевались постоянными и одинаковыми для всех пациентов;

5. в расчетах использовались значения параметров артерий у пациентов c изолированной патологической извитостью внутренних сонных артерий, т.е. при отсутствии признаков стенозирующего атеросклеротического поражения.

Статистическая обработка данных проводилась при помощи пакета прикладных программ Statistica 6,0 описательными и непараметрическими методами.

\section{РЕЗУЛЬТАТЫ И ОБСУЖДЕНИЯ}

Изучение нарушений гемодинамики при различных формах патологической извитости сонных артерий осуществлялось на основе результатов, полученных инструментальными клиническими методами в рамках предоперационного обследования. Отбор пациентов, имеющих патологическую извитость сонных артерий c изолированной гемодинамически значимой патологической извитостью, осуществлялся по результатам ультразвукового дуплексного сканирования сосудов шеи, которое было выполнено у 1375 лиц с проявлениями каротидной и/или вертебробазилярной сосудистой недостаточности.

Независимо от степени сосудистой мозговой недостаточности, гемодинамически значимая патологическая извитость сонных артерий являлась показанием к выполнению спиральной компьютерной томографии с контрастированием и последующей $3 D$-реконструкцией для уточнения диагноза, определения показаний и условий к оперативному лечению. Сочетание патологической извитости внутренней сонной артерии с атеросклеротическим поражением сонных артерий без гемодинамически значимого стенозирования просвета сосуда (степень стеноза менее $50 \%)$ по данным дуплексного сканирования также требовало проведения спиральной компьютерной томографии для уточнения степени стеноза и решения вопроса о возможности использования полученных данных при дальнейшем анализе. Пациенты со степенью стеноза более $30 \%$ по данным спиральной компьютерной томографии с контрастированием независимо от конфигурации патологически извитой внутренней сонной артерии исключались из последующего анализа. Магнитно-резонансная томография сосудов системы брахиоцефальных артерий выполнялась только в том случае, если по данным дуплексного сканирования не было выявлено стенотического поражения, а значение комплекса интима - медиа составляло менее 1,3. Необходимо указать включение в исследование семи пациентов с сочетанным стенозирующим атеросклеротическим поражением; степень стеноза во всех случаях рассчитывалась путем обработки полученных изображений с помощью программного обеспечения рабочей станции томографа и составила менее $30 \%$; во всех случаях локализация стеноза соответствовала бифуркации общей сонной артерии с переходом на устье внутренней сонной артерии. Такая степень стенозирования определялась как гемодинамически незначимая, а влияние таких атеросклеротических бляшек на кровоток при расчетах гемодинамических параметров не учитывалось. Три пациента 
были исключены из анализа, т.к. по данным спиральной компьютерной томографии с контрастированием был выявлен ангулярный перегиб в области колена патологического изгиба (сужение просвета артерии более 50 \%).

Ультразвуковое обследование сосудов шеи выявило патологическую извитость внутренних сонных артерий у 308 пациентов (22,4\%). Из них в 131 случае была диагностирована гемодинамически значимая патологическая извитость внутренней сонной артерии (42,5\%). Двухсторонний характер извитости обнаружен у 127 пациентов (41,2 \%), двухсторонняя гемодинамически значимая патологическая извитость внутренней сонной артерии наблюдалась у 35 пациентов $(11,4 \%)$.

Геометрические характеристики внутренней сонной артерии, как и все соматометрические показатели, зависят от соотношения массы тела и роста, индекса массы тела. В нашем исследовании медианы, нижние и верхние квартили указанных параметров имеют следующие значения: масса тела - $75(66 ; 85)$ кг, рост - 1,64 $(1,6 ; 1,7)$ м, индекс массы тела - 24,2 $(24,8 ; 31,2)$. Геометрические параметры сонных артерий при патологической извитости, используемые для оценки нарушений церебральной гемодинамики, определены по данным спиральной компьютерной томографии с контрастированием у 76 пациентов и магнитно-резонансной томографии у 9 пациентов с последующей $3 D$-реконструкцией интересующей зоны (85 пациентов).

Полученные $3 D$-реконструкции позволяют наиболее точно оценить геометрическую конфигурацию сонных артерий и верифицировать форму патологической извитости внутренней сонной артерии в соответствии с наиболее распространенной классификацией по Weibel, Fields and Metz [15]. C- и S-образные формы патологической извитости (при которых между двумя сегментами артерии образуется угол больше 90) верифицированы в 14 случаях; кинкинг внутренней сонной артерии - в 66 случаях «мягкий» кинкинг (форма патологической извитости со значениями углов изгибов от 61 до 90) - у 29 пациентов, умеренный кинкинг (со значениями углов изгибов от 31 до $60^{\circ}$ ) - у 28 пациентов, выраженный кинкинг внутренней сонной артерии (со значениями углов изгибов менее $30^{\circ}$ ) - у 9 пациентов; у 5 пациентов форма патологической извитости внутренней сонной артерии в одной из проекций напоминала петлю или спираль, что позволило верифицировать койлинг внутренней сонной артерии. Однако анализ выраженности гемодинамических нарушений и выбор оптимальной проекции $3 D$-реконструкции внутренней сонной артерии позволил представить данную форму извитости как последовательность плавных поворотов артерии с различными значениями углов этих поворотов. Полученные данные позволяют соотнести данную форму патологической извитости по характеру гемодинамических нарушений с «умеренным» кинкингом. Последующий статистический анализ изучаемых параметров осуществлялся для пациентов с койлингом и умеренным кинкингом совокупно. По результатам спиральной компьютерной томографии с контрастированием и магнитно-резонансной томографии с последующими $3 D$-реконструкциями интересующей зоны односторонняя патологическая извитость внутренней сонной артерии верифицирована в 27 (31,7 \%) случаях, двухсторонняя патологическая извитость - 58 (68,3\%).

Порог возникновения турбулентных течений в любом сосуде зависит от его внутреннего диаметра. Изменение скоростных параметров кровотока в патологически извитых артериях и распространенное сочетание изучаемой патологии с артериальной гипертензией, которая оказывает действие на стенки измененных артерий, позволяет предположить изменение диаметра артерий при патологической извитости в сравнении с нормой. Параметры геометрии сосудов зависят от антропометрических особенностей индивидуума, поэтому изучение изменений диаметра сонных артерий при патологической извитости внутренней сонной артерии осуществлялось сравнением 
значений морфометрических параметров у 27 пациентов с верифицированной односторонней извитостью внутренней сонной артерии и у 12 пациентов с кинкингом внутренней сонной артерии, сочетающимся с $S$ - или $C$-образной извитостью внутренней сонной артерии на контралатеральной стороне (значение угла патологического изгиба более $120^{\circ}$ ).

Сравнивались диаметры общих сонных артерий ниже бифуркации, общих сонных артерий в области бифуркации, устьев внутренней сонной артерии, диаметра внутренней сонной артерии в области колена изгиба с диаметром внутренней сонной артерии скелетотопически симметричной области на контралатеральной стороне, диаметров внутренней сонной артерии в субкраниальном отделе. Анализ выполнялся на основе стандартных двухмерных срезов в программе Centricity DICOM viewer 3,0, позволяющей измерить внутренний диаметр с точностью 10 мкм. Такой метод является более точным по сравнению с определением диаметра артерий на $3 D$-реконструкциях изучаемых сосудов, т.к. последние отражают только внутрипросветный диаметр артерии. Измерение диаметра внутренней сонной артерии в области колена патологического изгиба проводили путем совокупного анализа двухмерных срезов; для определения локализации колена патологического изгиба и симметричного участка артерии на контралатеральной стороне использовали $3 D$-реконструкции интересующей зоны.

Результаты измерений диаметра сосудов представлены в табл. 1 и 2 с указанием медиан, верхних и нижних квартилей $\left(M e\left(Q_{1} ; Q_{3}\right)\right)$.

Анализ диаметра общих сонных артерий в двух симметричных участках выявил отсутствие статистически значимых различий между исследуемыми группами, $p>0,1$ (критерий Колмогорова-Смирнова).

Также не было выявлено статистически значимых различий между диаметром внутренней сонной артерии в области колена изгиба в группе патологически извитых сонных артерий и диаметром симметричных (скелетотопически) участков внутренней сонной артерии на здоровой стороне ( $p>0,05$ - критерий Колмогорова-Смирнова).

Таблий 1

Диаметр общих сонных артерий при патологической извитости

\begin{tabular}{|c|c|c|}
\hline Группа & Общая сонная артерия, мм & $\begin{array}{c}\text { Бифуркация общей сонной } \\
\text { артерии, мм }\end{array}$ \\
\hline На стороне извитости $(n=39)$ & $7,31(6,87 ; 7,71)$ & $9,30(8,97 ; 9,65)$ \\
\hline $\begin{array}{c}\text { Контралатеральная сторона } \\
(n=39)\end{array}$ & $7,28(6,92 ; 7,66)$ & $9,12(8,88 ; 9,38)$ \\
\hline
\end{tabular}

Таблица 2

Диаметр патологически извитых внутренних сонных артерий

\begin{tabular}{|c|c|c|c|}
\hline Группа & $\begin{array}{c}\text { Устье внутренней } \\
\text { сонной артерии, мм }\end{array}$ & $\begin{array}{c}\text { Внутренняя сонная } \\
\text { артерия на уровне } \\
\text { колена изгиба, мм }\end{array}$ & $\begin{array}{c}\text { Субкраниальная } \\
\text { часть внутренней } \\
\text { сонной артерии, мм }\end{array}$ \\
\hline $\begin{array}{c}\text { На стороне извитости } \\
(n=39)\end{array}$ & $6,54(6,05 ; 7,64)$ & $5,07(4,75 ; 5,27)$ & $4,8(4,52 ; 5,2)$ \\
\hline $\begin{array}{c}\text { Контралатеральная } \\
\text { сторона }(n=39)\end{array}$ & $5,66(5,02 ; 6,17)$ & $5,04(4,72 ; 5,24)$ & $4,25(4,19 ; 4,54)$ \\
\hline
\end{tabular}


Однако полученные результаты свидетельствуют о статистически значимо большем диаметре внутренней сонной артерии в области устья и субкраниальном участке в группе патологически извитых сонных артерий $(p<0,001)$, что может свидетельствовать о гемодинамическом влиянии на стенки сосуда.

Течение крови в сонных артериях при условии их нормальной прямолинейной ориентации происходит в ламинарном режиме. Этот режим течения крови является наименее энергозатратным, поскольку трение между слоями жидкости в этих условиях минимально. Гипотеза о гемодинамической значимости извитости сонных артерий основана на появлении вихревых потоков крови при прохождении непосредственно участка изменения геометрической конфигурации артерии, что вызывает потерю давления на выходе из измененного участка. При патологической извитости внутренней сонной артерии переход от ламинарного течения крови к турбулентному регистрируется при выполнении ультразвукового дуплексного сканирования. Описанные изменения свидетельствуют о потерях давления и энергии на патологически измененном участке, что подтверждается результатами расчета показателей гемодинамики. Учитывая более частую встречаемость извитости внутренней сонной артерии, а также ее определяющую роль в кровоснабжении головного мозга, принято решение об использовании соответствующих геометрических характеристик для моделирования кровотока при патологической извитости сонных артерий.

Режим течения крови в сосуде характеризует безразмерное число Рейнольдса $(\operatorname{Re})[11,14]$, рассчитываемое по формуле

$$
\operatorname{Re}=\frac{\rho v d}{\mu},
$$

где $\rho$ - плотность крови, $v$ - скорость кровотока в сосуде, $d$ - диаметр сосуда, $\mu-$ динамическая вязкость крови.

Число Рейнольдса является индивидуальным для каждого отдельно взятого сосуда, т.к. зависит от диаметра последнего и скорости кровотока, в то время как вязкость и плотность крови достаточно стабильны для всей кровеносной системы пациента.

В расчетах использовались значения диаметра внутренней сонной артерии в области колена патологического изгиба с вариациями в узких пределах от 4,1 мм до 5,91 мм, $M e\left(Q_{1} ; Q_{3}\right)-5,07(4,75 ; 5,27)$. При вычислении числа Рейнольдса диаметр сосуда на всем протяжении условно был принят постоянным, равным диаметру в области колена патологического изгиба для минимального, среднего и максимального значений 4, 5 и 6 мм соответственно.

Скоростные характеристики кровотока, использованные при определении числа Рейнольдса, были получены посредством ультразвукового дуплексного сканирования сосудов шеи при патологической извитости внутренней сонной артерии. Как видно из табл. 3, максимальная линейная скорость кровотока зависит от степени патологической извитости (чем острее углы патологических изгибов, тем выше скорость кровотока).

В результате многофакторного анализа получены статистически значимые различия между группами по показателям максимальной скорости кровотока по Kruscal-Wallis ANOVA $(p<0,001 ; H(d f=3)=43,9)$. Корреляционный тест Spearman подтверждает сильную обратную статистически значимую зависимость максимальной скорости кровотока от угла патологического изгиба $(x=-0,77 ; p<0,05)$. Таким образом, наиболее острый угол в конфигурации патологической извитости может характеризовать гемодинамические нарушения в целом, хотя и не отражает полностью всех изменений, возникающих при движении крови по сосуду более сложной 
Таблица 3

Значения максимальной линейной скорости кровотока в области колена патологического изгиба (см/с) для различных форм патологической извитости внутренней сонной артерии

\begin{tabular}{|c|c|c|}
\hline Угол & $M e\left(Q_{1} ; Q_{3}\right)$ & Количество, $n$ \\
\hline Устье внутренней сонной артерии & $60(54 ; 70)$ & 85 \\
\hline $91^{\circ}$ и более & $140(120 ; 150)$ & 14 \\
\hline $61-90^{\circ}$ & $145(140 ; 160)$ & 29 \\
\hline $31-60^{\circ}$ & $172(152 ; 190)$ & 9 \\
\hline $30^{\circ}$ и менее & $210(200 ; 250)$ & 33 \\
\hline
\end{tabular}

геометрической конфигурации. Необходимо отметить, что скоростные характеристики кровотокау пациентов с патологической извитостью, имеющей углы изгибов более $91^{\circ}$, сопоставимы с данными в группе пациентов с углами изгибов от 61 до 90. Статистический анализ не выявил различий между данными группами по показателю максимальной линейной скорости кровотока $(p=0,18$ - критерий Манна-Уитни с поправкой Бонферрони). Таким образом, последующие результаты расчетов показателей гемодинамики не отражают изменений, возникающих при патологической извитости с углами более $91^{\circ}$, а характеризуют единый подход к отбору пациентов при решении вопроса о необходимости хирургического лечения патологической извитости, вошедших в исследование.

При прохождении по патологическому изгибу происходит ускорение тока крови. Как отмечено выше, в исследование были включены только пациенты с гемодинамически значимой патологической извитостью с приростом скорости кровотока в два и более раз, у которых в клинической картине преобладали признаки каротидной сосудистой мозговой недостаточности. С учетом существенной разницы между скоростью кровотока в начальном отделе внутренней сонной артерии и максимальной скоростью кровотока в области колена патологического изгиба полученные скоростные характеристики варьируют в широких пределах. В расчетах использовались следующие константы: динамическая вязкость 0,005 Па·с, плотность

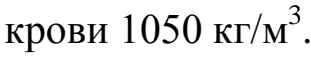

Критерием для определения режима течения крови по сосуду является сравнение расчетного числа Рейнольдса с его критическим значением $\mathrm{Re}^{\mathrm{\kappa p}}$, определяемым экспериментально. Если $\mathrm{Re}<\mathrm{Re}^{\text {кр }}$, ток крови ламинарный, если $\mathrm{Re}>$ $\mathrm{Re}^{\mathrm{kp}}$ - турбулентный [1, 12]. В частности, Coulter и Pappenheimer в 1949 г. нашли критическое значение числа Рейнольдса для крови в интервале от 820 до $1140(M \pm \sigma$

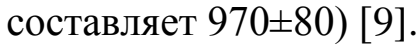

Расчет числа Рейнольдса позволяет определить условия, определяющие роль изучаемой патологии в нарушении мозгового кровообращения. Так, в артериях с внутренним диаметром 4 мм появление пристеночных турбулентных течений крови происходит при скорости 1,2 м/с, а полная турбулизация течения наступает при скорости 1,4 м/с. Во внутренних сонных артериях с большим диаметром, близким к 6 мм, скорость кровотока, при котором происходит появление пристеночных вихревых течений, равна $0,8 \mathrm{~m} / \mathrm{c}$, а турбулентный кровоток регистрируется при скорости $1 \mathrm{~m} / \mathrm{c}$. Таким образом, для пациентов с патологической извитостью внутренней сонной артерии, вошедших в исследование, характерен переходный и/или турбулентный режим тока крови, что подтверждает гемодинамическую значимость изучаемой патологии и косвенно указывает на нарушение перфузии головного мозга. Результаты математических расчетов подтверждаются признаками турбулизации кровотока во время выполнения ультразвукового исследования сонных артерий у данной группы пациентов. 
При ламинарном течении в извитой внутренней сонной артерии в местах изменения геометрии сосуда могут появляться вихревые зоны, которые уменьшают гидравлический диаметр основного потока. Это подтверждается регистрацией увеличения скорости кровотока при патологической извитости артерий инструментальными методами.

Объемный расход крови на участке между двумя сечениями патологически извитой внутренней сонной артерии является постоянной величиной и описывается уравнением неразрывности движения потока:

$$
Q=S_{1} v_{1}=S_{2} v_{2}=S_{n} v_{n}=\text { const },
$$

где $Q$ - объемный расход, $S$ - площадь поперечного сечения сосуда, $v$ - скорость кровотока в сосуде.

Из представленного уравнения следует, что скорость крови обратно пропорциональна площади поперечного сечения артерии $\left(S_{2} / S_{1}=v_{1} / v_{2}\right)$. Поскольку при патологической извитости внутренней сонной артерии по данным дуплексного сканирования сосудов шеи наблюдается значимый прирост скорости кровотока и отсутствие резких изменений внутреннего диаметра внутренней сонной артерии в местах изменения геометрии артерии по данным спиральной компьютерной томографии с контрастированием и 3D-реконструкции, можно сделать вывод о возникновении функционального стеноза. Описанную обратную пропорциональную зависимость можно представить следующим образом: при увеличении скорости кровотока в два раза происходит функциональное уменьшение площади поперечного сечения на $50 \%$, а трехкратный прирост скорости кровотока свидетельствует о функциональном стенозировании на $66,7 \%$.

Однако отождествлять нарушения гемодинамики вследствие функционального стенозирования с нарушениями при органических стенозах при атеросклеротическом поражении некорректно, поскольку в области бляшки также происходит переход от ламинарного к турбулентному режиму тока крови со значительным уменьшением гидравлического диаметра и площадью поперечного сечения в сравнении с истинным просветом артерии. Кроме того, выводы, основанные только на изменении скорости кровотока, не являются правомерными, поскольку ультразвуковое исследование имеет ряд ограничений процедуры измерения (аппарат- и оператор-зависимое исследование).

Определение режима тока крови необходимо для расчета потери давления при прохождении кровью патологического изгиба. Коэффициент местного сопротивления при ламинарном и близких к нему режимах течения зависит от числа Рейнольдса, а в условиях турбулентного тока крови зависит только от геометрической конфигурации сосуда [1]. Геометрия сосудистой системы у каждого пациента с патологической извитостью сонных артерий имеет свои особенности, однако можно выделить ряд структурных компонентов, которые являются причиной потери напора и энергии (участки сужения и расширения, патологические изгибы, стенозы и т.п.). Потери напора на участках местного сопротивления у пациентов с патологической извитостью внутренней сонной артерии целесообразно определять только расчетными методами, поскольку инвазивные методики измерения давления сопровождаются риском развития осложнений и являются дорогостоящими.

Потери напора в месте изгиба (местные потери) рассчитываются по формуле Вейсбаха:

$$
h_{a n}=\zeta_{a n} \frac{v^{2}}{2 g},
$$

где $\zeta_{a n}$ - коэффициент сопротивления плавного поворота, $v$ - скорость кровотока в области колена патологического изгиба, $g$ - ускорение свободного падения. 
Патологически измененный участок внутренней сонной артерии, как правило, имеет сложную форму с различными углами и радиусами поворота, которую можно представить в виде последовательности плавных поворотов на угол $\theta$. Для кровеносной системы коэффициент плавного поворота можно найти по формуле

$$
\zeta_{a n}=\zeta_{\text {an }} \frac{\theta}{90^{\circ}}
$$

где $\zeta_{a n}$ - коэффициент сопротивления при $\theta=90^{\circ}$.

Коэффициент $\zeta_{a n}$ может быть определен по формуле:

$$
\zeta_{\text {an }}=0,131+0,163\left(\frac{d}{R_{0}}\right)^{3,5},
$$

где $d$ - диаметр сосуда; $R_{0}$ - радиус плавного поворота.

Современные возможности программного обеспечения рабочей станции компьютерного томографа позволяют выполнять 3D-реконструкцию интересующей зоны. Данный метод позволяет дополнить полученную на двухмерных срезах информацию, а также выбрать оптимальную проекцию для последующего исследования и анализа, уникальную для каждого пациента (индивидуальный ракурс). Анализ 3D-реконструкции патологически извитой внутренней сонной артерии позволяет измерить длину артерии, углы и радиусы поворота патологических изгибов с максимальной точностью.

Коэффициент плавного поворота рассчитывался для каждой патологически извитой внутренней сонной артерии. На рис. 1 показано измерение параметров, необходимых для расчета местных потерь энергии, обусловленных гидродинамическим трением на участке патологического изгиба. Использовалось изображение, полученное по приведенной ниже схеме путем 3D-реконструкции срезов спиральной компьютерной томографии с контрастированием.

Результаты измерений диаметра внутренней сонной артерии в области колена патологического изгиба и радиуса поворота сосуда представлены в табл. 4.

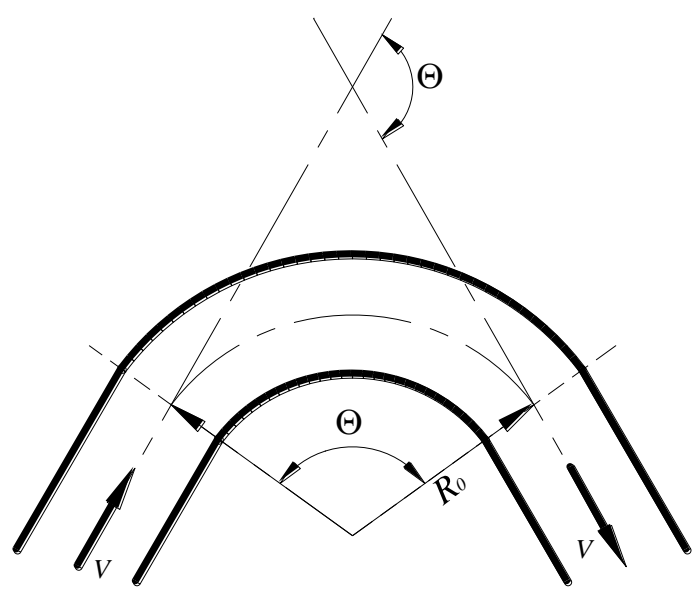

$a$

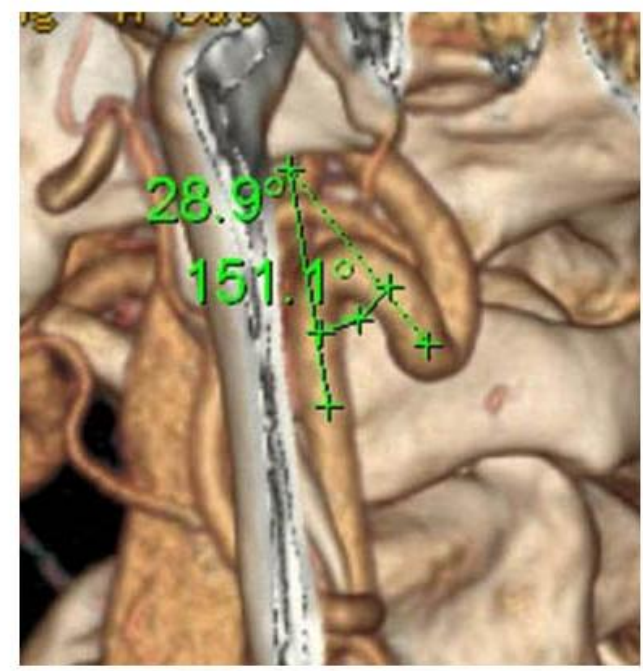

6

Рис. 1. Схема измерения углов патологического изгиба и плавного поворота сосудов $(a)$ и изображение интересующей зоны (б) в программе Centricity DICOM viewer 3,0: $\sigma$ - угол патологического изгиба; $\theta$ - угол плавного поворота; $R_{0}$ - радиус плавного поворота; $v$ - направление тока крови в сосуде 
Таблицьа 4

Значения диаметра и радиуса поворота сосуда в зависимости от остроты угла патологического изгиба внутренней сонной артерии $\left(M e\left(Q_{1} ; Q_{3}\right)\right)$

\begin{tabular}{|c|c|c|c|}
\hline Угол изгиба & $\begin{array}{c}\text { Диаметр внутренней } \\
\text { сонной артерии } d, \text { мм }\end{array}$ & $\begin{array}{c}\text { Радиус поворота извитого } \\
\text { сосуда } R_{0}, \text { мм }\end{array}$ & $\begin{array}{c}\text { Число } \\
\text { наблюдений }\end{array}$ \\
\hline $91^{\circ}$ и более & $4,93(4,74 ; 5,11)$ & $5,94(5,27 ; 6,5)$ & 14 \\
\hline $61-90^{\circ}$ & $5,06(4,87 ; 5,43)$ & $5,35(4,92 ; 5,85)$ & 29 \\
\hline $31-60^{\circ}$ & $4,99(4,67 ; 5,27)$ & $4,95(4,5 ; 5,25)$ & 9 \\
\hline $30^{\circ}$ и менее & $5,03(4,85 ; 5,25)$ & $4,8(4,17 ; 4,95)$ & 33 \\
\hline
\end{tabular}

Исходя из многофакторного анализа, установлено отсутствие статистически значимых различий между группами по показателю диаметра внутренней сонной артерии в области колена патологического изгиба согласно Kruscal-Wallis ANOVA $(p=0,53 ; \quad H(d f=3)=2,21)$. Значения радиуса поворота в изучаемых группах статистически различаются по Kruscal-Wallis ANOVA $(p<0,001 ; H(d f=3)=75,33)$. Также выявлена прямая статистически значимая зависимость средней силы между радиусом поворота и углом патологического изгиба - корреляционный тест Spearman $(x=0,73 ; p<0,05)$. Таким образом, выявлена тенденция увеличения радиуса поворота при увеличении значения угла патологического изгиба.

В свою очередь, ток крови по патологически извитым сосудам с большим радиусом поворота является менее энергозатратным. Формирование патологической извитости с радиусом поворота, равным или меньшим по сравнению с диаметром артерии, связано с «плотной» укладкой артерии в данной анатомической области из-за ограниченного пространства формирования извитости. Наличие изгиба с таким значением радиуса поворота свидетельствует о сложной конфигурации артерии и является причиной формирования следующего изгиба с аналогичными выраженными нарушениями гемодинамики.

Результаты расчетов для наиболее выраженного (наиболее острого) изгиба представлены в табл. 5.

Значения коэффициента сопротивления и местных потерь напора в изучаемых группах статистически различаются по Kruscal-Wallis ANOVA ( $<$ <0,001; $H(d f=3)=63,2 ; \quad p<0,001 ; \quad H(d f=3)=58,7$ соответственно $)$. Корреляционный тест Spearman подтверждает сильную обратную статистически значимую зависимость между значениями угла патологического изгиба и местными потерями напора на плавный поворот $(x=-0,90 ; p<0,05)$. Полученные данные свидетельствуют,

Таблиия 5

Оценка местных потерь напора для различных углов патологического изгиба внутренней сонной артерии $\left(M e\left(Q_{1} ; Q_{3}\right)\right)$

\begin{tabular}{|c|c|c|c|}
\hline Угол изгиба & $\begin{array}{c}\text { Коэффициент } \\
\text { сопротивления плавного } \\
\text { поворота }\end{array}$ & $\begin{array}{c}\text { Местные потери напора } \\
\text { на плавный поворот }\end{array}$ & $\begin{array}{c}\text { Число } \\
\text { наблюдений }\end{array}$ \\
\hline $91^{\circ}$ и более & $0,203(0,18 ; 0,227)$ & $0,019(0,013 ; 0,025)$ & 14 \\
\hline $61-90^{\circ}$ & $0,321(0,295 ; 0,372)$ & $0,033(0,028 ; 0,043)$ & 29 \\
\hline $31-60^{\circ}$ & $0,477(0,443 ; 0,517)$ & $0,072(0,059 ; 0,098)$ & 33 \\
\hline $30^{\circ}$ и менее & $0,548(0,533 ; 0,654)$ & $0,127(0,119 ; 0,234)$ & 9 \\
\hline
\end{tabular}


что в извитых участках сонных артерий с углами изгибов более $90^{\circ}$ ток крови претерпевает значительно меньшее сопротивление на трение, обусловленное плавным поворотом сосуда, а изгибы артерии имеют большее значение радиуса поворота.

При формировании $C$-образной патологической извитости происходит плавный поворот артерии как минимум в трех точках; принципиально меняются только значения радиуса и угла плавного поворота. При прохождении крови по патологически извитому сосуду падение давления происходит на каждом изгибе из-за возрастающего сопротивления, однако общее сопротивление нельзя определить как сумму сопротивлений при прохождении каждого изгиба. Этот факт объясняется тем, что гидродинамическое трение является функцией скорости. При прохождении крови по патологическому изгибу происходит ускорение кровотока, а на участке сосуда за изгибом происходит падение скорости, следовательно, уменьшается и сопротивление при прохождении кровью последующего колена патологически извитой артерии. Теоретически возможен расчет абсолютной потери давления для извитых артерий любой конфигурации. Однако при дуплексном сканировании невозможно точно измерить скорость кровотока во всех интересующих сегментах артерии, кроме того, определение скорости кровотока при субкраниальных формах патологической извитости внутренней сонной артерии технически трудновыполнимо. Поэтому в расчетах гемодинамических параметров использовали максимальную скорость кровотока в области колена патологического изгиба, регистрируемую по результатам дуплексного сканирования, и величину наиболее выраженного изгиба в системе патологически извитой артерии по данным спиральной компьютерной томографии с контрастированием или магнитно-резонансной томографии.

Для оценки значимости потери напора на трение по длине предлагается ввести понятие избытка длины сосуда, в результате которого возникают конфигурационные аномалии и гемодинамические нарушения. Избыток длины артерии при патологической извитости приводит к увеличению потери напора на трение по сравнению с прямолинейными сонными артериями нормальной длины. Для учета потери давления при прохождении кровью большего расстояния при патологической извитости выполнены измерения длины сосудов. В норме ток крови сопровождается потерями давления и энергии по длине сосуда, однако эти потери незначительны, поскольку они возникают в условиях ламинарного тока крови в пределах нормальных показателей скоростных характеристик кровотока. Длина внутренней сонной артерии при патологической извитости по результатам нашего исследования колеблется от 74 до 140 мм, медиана и интерквартильный размах $M e\left(Q_{1} ; Q_{3}\right)$ составили 101 мм $(88 ; 120)$.

Однако движение крови по извитой внутренней сонной артерии в турбулентном режиме осуществляется не по всей длине артерии. Появление вихревых зон тока крови происходит непосредственно на участке изменения геометрии сосуда, а именно, при прохождении патологического изгиба артерии. Потеря напора на плавном повороте вызывает потерю давления на трение по длине, непосредственно зависящую от длины участка, на котором возникает изменение режима тока крови. Гипотетически именно на таком протяжении происходят изменения гемодинамики, приводящие к нарушению церебрального кровотока и данный отрезок внутренней сонной артерии при патологической извитости принят за «участок гемодинамических нарушений». Потеря давления по длине складывается из потери давления на трение о стенки сосуда, которое в условиях отсутствия атеросклеротического поражения является минимальным, и потери давления на трение слоев (вихрей) крови между собой. 
Длина участка гемодинамических нарушений принята равной расстоянию от первого колена патологического изгиба артерии до входа внутренней сонной артерии в височную кость. На данном участке происходит регистрация максимальной скорости кровотока, которая была использована в расчетах, а диаметр внутренней сонной артерии можно принять постоянным и равным значению диаметра в области колена патологического изгиба.

Потеря напора (энергии) на трение по длине патологически извитого сосуда определяется по формуле Дарси

$$
h_{l}=\lambda \frac{l}{d} \frac{v^{2}}{2 g},
$$

где $\lambda$ - коэффициент потери на трение по длине (коэффициент Дарси), $l$ - длина сосуда, $d$ - диаметр сосуда, $v$ - скорость кровотока в области колена патологического изгиба, $g$ - ускорение свободного падения.

Медианы и интерквартильный размах параметров длины патологически извитой внутренней сонной артерии представлены в табл. 6.

Значения длины внутренней сонной артерии в изучаемых группах статистически различаются по Kruscal-Wallis ANOVA $(p=0,027 ; \quad H(d f=3)=9,16)$. Тенденция увеличения длины внутренней сонной артерии при уменьшении угла патологического изгиба подтверждается статистически значимой обратной зависимостью средней силы (корреляционный тест Spearman, $x=-0,31 ; p=0,003$ ). Избыток длины внутренней сонной артерии играет ключевую роль в формировании патологической извитости; чем больше длина внутренней сонной артерии, тем сложнее ее геометрическая конфигурация. Данная гипотеза основана на том, что процесс формирования конфигурационных аномалий происходит на ограниченном участке артерии между интракраниальной частью внутренней сонной артерии и бифуркацией общей сонной артерии, фиксированной за счет ветвей наружной сонной артерии. Таким образом, для формирования извитостей с острыми углами необходим больший избыток длины сосуда. Это косвенно подтверждается статистически значимо меньшим значением радиуса поворота извитой артерии при извитостях с острыми углами.

Расчет потери напора на трение по длине патологически извитого сосуда выполнялся при следующих допущениях: диаметр сосуда принимался за постоянную величину, равную диаметру внутренней сонной артерии в области колена патологического изгиба. Расчет коэффициента Дарси выполнялся для извитостей, по которым ток крови происходит в турбулентном режиме. Результаты расчета коэффициента Дарси представлены на рис. 2 в виде графика, позволяющего определять значение данного коэффициента, исходя из известного числа Рейнольдса.

Таблица 6

Длина внутренней сонной артерии и участка гемодинамических нарушений для различных углов патологического изгиба $\left(M e\left(Q_{1} ; Q_{3}\right)\right)$

\begin{tabular}{|c|c|c|}
\hline Угол изгиба & $l$, мм & $l_{\text {уч. гем. нар }, \text { мм }}$ \\
\hline $91^{\circ}$ и более $(n=14)$ & $94,5(88 ; 110)$ & $57(45 ; 71)$ \\
\hline $61-90^{\circ}(n=29)$ & $97(85 ; 107)$ & $63(54 ; 82)$ \\
\hline $31-60^{\circ}(n=33)$ & $104(100 ; 113)$ & $77(64 ; 85)$ \\
\hline $30^{\circ}$ и менее $(n=9)$ & $100(100 ; 110)$ & $78(76 ; 88)$ \\
\hline
\end{tabular}

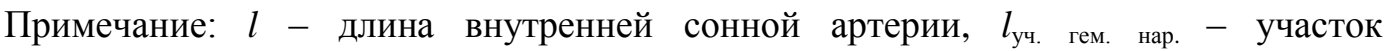
гемодинамических нарушений (расстояние от первого колена патологически извитой артерии до входа внутренней сонной артерии в височную кость). 


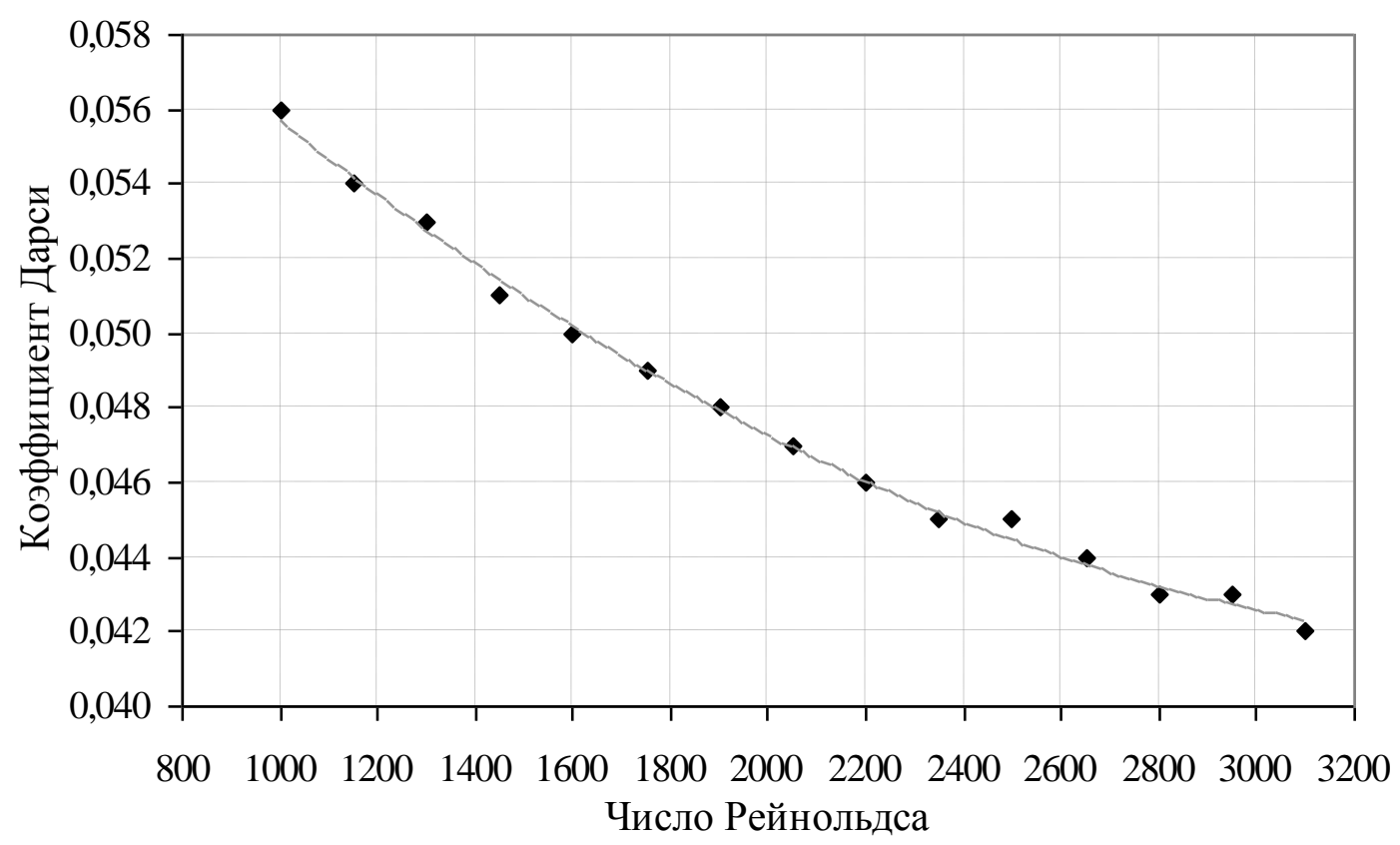

Рис. 2. Графическая зависимость для определения коэффициента Дарси

Вычисление коэффициента Дарси для сосудов системы брахиоцефальных артерий при патологической извитости сонных артерий выполнено по формуле Блазиуса (7) (условия: зона гидравлически гладкой трубы и турбулентный режим тока крови):

$$
\lambda=\frac{0,3164}{\operatorname{Re}^{0,25}} .
$$

Как видно из рис. 2, коэффициент Дарси варьируется в сравнительно узких пределах и для турбулентного тока крови, возникающего в патологически извитых сонных артериях, он колеблется от 0,042 до 0,056 . Однако при определении данного коэффициента необходимо учитывать число Рейнольдса, отражающего скорость кровотока и диаметр сосуда, индивидуальные для каждого пациента, что позволяет в более широком ракурсе оценить гемодинамические потери. Дальнейший расчет потери напора на трение по длине выполнялся для участка внутренней сонной артерии от первого колена патологической извитости до входа внутренней сонной артерии в височную кость. Результаты расчета коэффициента Дарси и местных потери напора по длине представлены в табл. 7.

Значения коэффициента Дарси и местных потерь напора на трение по длине в изучаемых группах статистически различаются по Kruscal-Wallis ANOVA ( $p<0,001$; $H(d f=3)=34,4 ; p<0,001 ; H(d f=3)=36,9$ соответственно $)$.

Таблица 7

Потери напора по длине внутренней сонной артерии для различных углов патологического изгиба $\left(M e\left(Q_{1} ; Q_{3}\right)\right.$

\begin{tabular}{|c|c|c|c|}
\hline Угол изгиба & Коэффициент Дарси & $\begin{array}{c}\text { Местные потери напора } \\
\text { по длине }\end{array}$ & $\begin{array}{c}\text { Число } \\
\text { наблюдений }\end{array}$ \\
\hline $91^{\circ}$ и более & $0,051(0,051 ; 0,052)$ & $0,057(0,039 ; 0,081)$ & 14 \\
\hline $61-90^{\circ}$ & $0,051(0,49 ; 0,51)$ & $0,068(0,055 ; 0,083)$ & 29 \\
\hline $31-60^{\circ}$ & $0,049(0,047 ; 0,05)$ & $0,109(0,088 ; 0,132)$ & 33 \\
\hline $30^{\circ}$ и менее & $0,046(0,044 ; 0,046)$ & $0,151(0,128 ; 0,245)$ & 9 \\
\hline
\end{tabular}


Суммарные потери давления на участке местного сопротивления рассчитываются следующим образом

$$
\Delta p=\rho g h_{a n}+\rho g h_{l},
$$

где $\rho$ - плотность крови, $g$ - ускорение свободного падения, $h_{a n}$ - местные потери напора на плавный поворот, $h_{1}-$ местные потери напора по длине извитой артерии.

Результаты расчета потерь давления на местное сопротивление (плавный поворот, трение по длине извитой внутренней сонной артерии и суммарная потеря давления) представлены в табл. 8.

Суммарная потеря давления при патологической извитости внутренней сонной артерий зависит от ряда факторов, комплексное использование которых позволяет охарактеризовать выраженность гемодинамических нарушений при сложной конфигурации измененной артерии. Полученные данные позволяют выявить статистически значимую сильную обратную зависимость между суммарными потерями давления и значением угла патологического изгиба внутренней сонной артерии (корреляционный тест Spearman $x=-0,84 ; p<0,05$ ), сильную прямую зависимость между потерей давления и максимальной скоростью кровотока $(x=0,93 ; p<0,05)$, прямую зависимость средней силы между потерей давления и отношением максимальной скорости к скорости кровотока в участке артерии, проксимальном по отношению к патологическому изгибу $(x=0,63 ; p<0,05)$, прямую зависимость средней силы между суммарной потерей давления и длиной патологически извитой артерии $(x=0,52 ; p<0,05)$, длиной артерии от первого колена патологического изгиба до входа в височную кость $(x=0,57 ; p<0,05)$, отношением истинной длины измененной артерии к условному расстоянию от устья внутренней сонной артерии до входа в височную кость $(x=0,63 ; p<0,05)$.

Таким образом, при увеличении скорости кровотока и длины измененной артерии, а также уменьшении углов патологических изгибов, имеют место более выраженные нарушения церебрального кровотока, обусловливающие гемодинамический механизм развития сосудистой мозговой недостаточности. Необходимость использования параметров длины вызвана возможностью изменения конфигурации патологической извитости артерии при изменении положения головы и шеи, поскольку длина артерии является постоянной величиной, индивидуальной для каждого пациента.

Таблица 8

Потеря давления при патологической извитости внутренней сонной артерии $\left(M e\left(Q_{1} ; Q_{3}\right)\right)$

\begin{tabular}{|c|c|c|c|}
\hline Угол изгиба & $\begin{array}{c}\text { Потеря давления } \\
\text { при прохождении плавного } \\
\text { поворота, Па (мм рт. ст.) }\end{array}$ & $\begin{array}{c}\text { Потеря давления } \\
\text { по длине, Па } \\
\text { (мм рт. ст.) }\end{array}$ & $\begin{array}{c}\text { Суммарная потеря } \\
\text { давления, Па } \\
\text { (мм. рт. ст.) }\end{array}$ \\
\hline $91^{\circ}$ и более & $193(142 ; 261)$ & $582(400 ; 833)$ & $775(531 ; 1108)$ \\
$(1,5(1,1 ; 1,9))$ & $(4,4(3,0 ; 6,3))$ & $(5,9(3,9 ; 8,4))$ \\
\hline $61-90^{\circ}$ & $338(289 ; 447)$ & $704(569 ; 852)$ & $1093(910 ; 1323)$ \\
$31-60^{\circ}$ & $(2,5(2,2 ; 3,4))$ & $(5,3(4,3 ; 6,4))$ & $(8,2(6,9 ; 9,9))$ \\
\hline $30^{\circ}$ и менее & $741(610 ; 1005)$ & $1128(903 ; 1359)$ & $1962(1513 ; 2204)$ \\
& $(5,6(5,5 ; 7,6))$ & $(8,5(6,8 ; 10,2))$ & $(14,7(11,4 ; 16,6))$ \\
\hline
\end{tabular}


Диаметр патологически извитой внутренней сонной артерии, исходя из уравнения Рейнольдса, имеет большое значение при определении режима тока крови. Так, при установленных значениях диаметра измененной артерии и скоростных показателей кровотока у обследованных пациентов ожидается появление вихревых (турбулентных) течений. Однако при оценке суммарной потери давления диаметр артерии является малозначащим фактором, так как статистически значимой зависимости между изучаемыми параметрами не было выявлено (корреляционный тест Spearman, $x=-0,08 ; p=0,44)$.

Относительная потеря давления на участке местного сопротивления рассчитывалась по следующей зависимости

$$
\Delta p_{\text {rel }}=\frac{\Delta p}{S B P} 100 \%,
$$

где $\Delta p$ - суммарная расчетная потеря давления; $S B P$ - систолическое артериальное давление.

Максимальное систолическое артериальное давление у пациентов с патологической извитостью внутренней сонной артерии в изучаемых группах статистически не различается по Kruscal-Wallis ANOVA $(p=0,1 ; H(d f=3)=6,25)$. Относительная потеря давления при патологической извитости внутренней сонной артерии в изучаемых группах статистически различается по Kruscal-Wallis ANOVA $(p<0,001 ; H(d f=3)=42,5)$. Выявлена сильная статистически значимая обратная зависимость между значением относительной потери давления и углом патологического изгиба (корреляционный тест Spearman, $x=-0,78 ; p<0,001$ ).

\section{Выводы}

1. Появление пристеночных вихревых потоков крови, смена ламинарного режима турбулентным при скорости кровотока более 1 м/c $(\operatorname{Re}>1140)$ и прирост скорости кровотока в результате уменьшения гидравлического диаметра приводят к увеличению потери энергии и артериального давления, что вызывает гипоперфузию головного мозга.

2. Диаметр устья внутренней сонной артерии при односторонней патологической извитости превышает диаметр устья внутренней сонной артерии на контралатеральной стороне (критерий Колмогорова-Смирнова $-p<0,001$ ), что свидетельствует о тенденции к расширению проксимального участка артерии по отношению к патологическому изгибу и косвенно указывает на гемодинамическую значимость извитости и затруднение тока крови при прохождении по извитому участку сосуда.

3. Биомеханический анализ кровотока позволил установить, что в артериях с внутренним диаметром 4 мм появление пристеночных турбулентных течений происходит при скорости 1,2 м/с, а полная турбулизация - при скорости 1,4 м/с. Во внутренних сонных артериях с большим диаметром, близким к 6 мм, скорость кровотока, при которой появляются пристеночные вихревые течения, составляет $0,8 \mathrm{M} / \mathrm{c}$, а турбулентный кровоток регистрируется при скорости $1 \mathrm{M} / \mathrm{c}$.

4. Степень гемодинамических нарушений при патологической извитости сонных артерий зависит от выраженности конфигурационных аномалий измененного сосуда, являющихся причиной появления турбулентного течения крови. При систематизации полученных данных по классификации Weibel, Fields and Metz, формирование выраженных кинкингов происходит на фоне увеличения длины сосуда $(p=0,027)$ и максимальной скорости кровотока $(p<0,001)$, уменьшения угла изгиба и радиуса поворота измененной артерии $(p<0,001)$, что приводит к увеличению потери 
давления от $8,2(6,9 ; 9,9)$ мм рт. ст. $(7,2(6,2 ; 8,8) \%)$ при «мягком» кинкинге до $20,8(19,4 ; 37,1)$ мм рт. ст. $(16,4(14,2 ; 29,9) \%)$ при выраженном кинкинге внутренней сонной артерии.

5. Комплексное использование анатомических и гемодинамических параметров позволяет оценить совокупную потерю давления и энергии, обусловленную трением на участке изменения геометрии артерии, трением о стенки сосуда и внутренним трением между слоями (вихрями) крови при патологической извитости внутренних сонных артерий любой геометрической конфигурации: значение наиболее выраженного угла патологического изгиба (корреляционный тест Spearman, $x=-0,84 ; p<0,05$ ), максимальной скорости кровотока $(x=0,93 ; p<0,05)$, отношения максимальной скорости кровотока к скорости на участке артерии проксимальном по отношению к патологическому изгибу $(x=0,63 ; p<0,05)$, отношения истинной длины измененной артерии к условному расстоянию, соединяющему устье внутренней сонной артерии с входом артерии в височную кость $(x=0,63 ; p<0,05)$.

\section{БЛАГОДАРНОСТИ}

Исследование выполнено при финансовой поддержке Государственной программы научных исследований «Конвергенция» (задание 3.5.04).

\section{СПИСОК ЛИТЕРАТУРЫ}

1. Вильнер Я.М., Ковалев Я.Т. Справочное пособие по гидравлике, гидромашинам и гидроприводам. Минск: Вышэйшая школа, 1976. - 416 с.

2. Гавриленко А.В., Куклина А.В., Кравченко А.А., Агафонов И.Н. Профилактика повторных ишемических инсультов // Ангиология и сосудистая хирургия. - 2008. - Т. 14, № 3. - С. 143-148.

3. Павлова О.Е., Иванов Д.В., Грамакова А.А., Морозов К.М., Суслов И.И. Гемодинамика и механическое поведение бифуркации сонной артерии с патологической извитостью // Известия Саратовского ун-та. Новая серия. - 2010. - Т. 10, № 2. - С. 66-73.

4. Покровский А.В., Белоярцев Д.Ф., Тимина И.Е., Адырхаев 3.А. Когда нужно оперировать патологическую деформацию внутренней сонной артерии? // Ангиология и сосудистая хирургия. 2010. - Т. 16, № 4. - С. 116-122.

5. Родин Ю.В. Исследование потоков крови при патологической $S$-образной извитости сонных артерий // Междун. неврологический журнал [Электронный ресурс]. - 2006. - Т. 4, № 8. - URL: www.mif-ua.com/archive/issue-2443/article-2465 (дата обращения: 19.01.2013).

6. Шилько С.В., Кузьминский Ю.Г., Саливончик С.П. Расчет характеристик пульсовой волны с учетом деформаций кровеносных сосудов // Российский журнал биомеханики. - 2001.- Т. 5, № 1. - С. 88-94.

7. Янушко В.А., Турлюк Д.В., Михневич В.Б. Клиника, диагностика и хирургическое лечение вертебробазилярной недостаточности // Кардиология в Беларуси. - 2008. - Т. 1, № 1. - С. 34-44.

8. Alnaes M.S., Isaksen J., Mardal K.A., Romner B., Morgan M.K., Ingebrigtsen T. Computation of hemodynamics in the circle of Willis // Stroke. - 2007. - Vol. 38. - P. 2500-2505.

9. Coulter N.A. Jr., Pappenheimer J.R. Development of turbulence in flowing blood // American Journal of Physiology. - 1949. - Vol. 159, № 2. - P. 401-408.

10. Han H.C. A biomechanical model of artery buckling // Journal of Biomechanics. - 2007. - Vol. 40. P. 3672-3678.

11. Kolachalama V.B., Levine E.G., Edelman E.R. Luminal flow amplifies stent-based drug deposition in arterial bifurcations // PLoS ONE [Electronic resource]. - 2009 . URL: www.plosone.org/article/info:doi\%2F10.1371\%2Fjournal.pone.0008105 (дата обращения: 02.06.2012)

12. Lew H.S., Fung Y.C. Entry flow into blood vessels at arbitrary Reynolds number // Journal of Biomechanics. - 1970. - Vol. 3. - P. 23-38.

13. Liu Q. Han H.C. Mechanical buckling of artery under pulsatile pressure // Journal of Biomechanics. 2012. - Vol. 45. - P. 1192-1198.

14. Mukundakrishnan K., Eckmann D.M., Ayyaswamy P.S. Bubble motion through a generalized power-law fluid flowing in a vertical tube // Ann. N. Y. Acad. Sci. - 2009. - Vol. 1161. - P. 256-267.

15. Togay-Isikay C., Betterman K., Andrews C., Maeds D. Carotid artery tortuosity, kinking, coiling : stroke risk factor, marker, or curiosity? // Acta Neurologica Belgica. - 2005. - Vol. 105. - P. 68-72. 


\title{
ROLE OF LOCAL HEMODYNAMIC ABNORMALITIES AT PATHOLOGIC TORTUOSITY OF THE CAROTID ARTERIES IN DEVELOPMENT OF VASCULAR CEREBRAL INSUFFICIENCY
}

\author{
M.L. Kaplan, D.N. Boncevich, S.V. Shilko (Gomel, Belarus)
}

Turbulence in blood flow in patients with pathological tortuosity of the internal carotid artery at a rate in excess of $1 \mathrm{~m} / \mathrm{s}(\operatorname{Re}>1140)$, the occurrence of wall surface vortices and increase of blood flow rate by reducing the hydraulic diameter of the arteries result in the increased hemodynamic resistance of the vasculature and the brain hypoperfusion. Variety of forms and the complexity of the geometric configuration of arteries in their pathological tortuosity require an individual approach in determining the indications for surgical treatment and the choice of method of operation. The paper describes the objective biomechanical criteria based on instrumental clinical studies of hemodynamic disturbances and determining the pressure gradient in the areas of changing the geometry of blood vessels. The integrated use of anatomic and hemodynamic parameters allows us to estimate the energy losses and pressure gradients in pathological tortuosity of the internal carotid arteries in any geometric configuration. The extension of the proximal portion of the artery with respect to the pathological curvature was found which caused by the fact that the diameter of the mouth of the carotid artery with unilateral pathological tortuosity exceeds diameter of the mouth on the contralateral side. It was showed the occurrence of parietal swirl flow corresponds to a rate of $1.2 \mathrm{~m} / \mathrm{s}$ and the total turbulence - at a speed of $1.4 \mathrm{~m} / \mathrm{s}$ in the arteries with diameter of $4 \mathrm{~mm}$. Flow rate at which a swirl flow is $0.8 \mathrm{~m} / \mathrm{s}$ and a turbulent blood flow is recorded at a rate of $1 \mathrm{~m} / \mathrm{s}$ by increasing the diameter of the carotid artery to $6 \mathrm{~mm}$.

Key words: pathological tortuosity of the carotid arteries, kinking, coiling, local hemodynamic abnormalities (disturbances), pressure gradient, energy loss. 